\title{
La casa como núcleo estructurador del espacio urbano en la novela del siglo XIX: Fortunata y Jacinta de B. Pérez Galdós y La febre d'or de N. Oller
}

\author{
Antonio Arroyo Almaraz
}

I.- A propósito de la espacialidad narrativa en la novela realista del ochocientos y centrándonos comparativamente en títulos señeros de las letras castellana y catalana, venimos ordenando una serie de propuestas derivadas de una investigación doctoral adecuadamente revisada y sometida a reconsideración 1 . En esta ocasión nos centraremos en un ámbito que aglutina un motivo de interesante rentabilidad en los parámetros narrativos del siglo XIX.

La ciudad, como afán de conjunto, se estructura en distintos ámbitos, uno de los cuales es el espacio de la privacidad, frente a lo público, que empieza a tener mayor significación en la narrativa decimonónica que en épocas anteriores. Su imagen de representación es la casa que simboliza la totalidad del individuo o individuos que la habitan; es una representación típica, pero con sus variantes no exentas de intención representativa. Honoré de Balzac, por ejemplo, distribuye París, en La peau de chagrin, entre la buhardilla del humilde

1 - Tesis Doctoral: El espacio ubano: Universo para una acción. La espacialidad narrativa en «Fortunata y Jacinta» de B.P.Galdós y en "La Febre d'or» de N. Oller. UCM. 1998.

- Artículo: «Benito Pérez Galdós y Narcís Oller: Formulación y pencepción narrativas de la ciudad». Revista de Lenguas y Literaturas Catalana, Gallega y Vasca $\mathbf{n}^{\circ}$ VI. UNED, 1998-99, pp.17-27

- Cominicación y artículo: «La relación norte-sur como eje estructurador de la poética urbana en la narrativa del siglo XIX: Fortunata y Jacinta y La febre $d$ orw. XIII Simposio de la Sociedad Española de Literatura General y Comparada. Universidad de León, octubre del 2000 (en preparación). 
hotel de Madame Gaudin donde va a parar Raphael de Valentin y los salones de la Condesa Fedora donde es presentado para así acceder a la vida artística. En $E l$ tío Goriot, la acción se centra entre la humillante casa de huéspedes de la patrona Vauquer donde se sume el anciano y el gran mundo parisino al que, merced a sus sacrificios, han accedido sus hijas casadas con sendo banquero y conde.

II.- En el ámbito peninsular, la narrativa correspondiente no será ajena ni a la formulación del espacio urbano, ni al de la correspondencia privacidad-casa, ni a los motivos que generan. En castellano y en catalán, Benito Pérez Galdós y Narcís Oller son partícipes de dichos planteamientos. Desde una perspectiva comparatista y en el marco del intercambio de opiniones que recogen sus epistolarios 2 , revisaremos el espacio de la privacidad. Respectivamente, en Fortunata y Jacinta y en La febre d'or ${ }^{3}$, encontraremos, por parte de Galdós y de Oller, diversas maneras de reflejar el espacio de la casa, en sus contextos barcelonés y madrileño, como uno de los ejes estructuradores del espacio narrativo. A partir de aquí surgirán distintos motivos literarios, por ejemplo:

- En un encuadre general, la casa es el espacio sobre el que se genera una circularidad en las novelas, con el consiguiente camino existencial recorrido que da sentido a la estructuración narrativa. Véase en Fortunata y Jacinta, primera parte, tercer capítulo: (I, III, II, pgs. 181 y ss.4), y cuarta parte, cuarto capítulo: (IV, IV, I, pgs. 405 y ss.). En La febre d'or, primera parte: (I, VI, pgs. 88 y ss.), y en segunda parte: (II, XIV, pgs. 465).

- Por otro lado, la casa es un reflejo o referencia del personaje, una de las distintas imágenes de representación que lo definen; lo cual nos lleva a la comprensión de este espacio como generador de emociones y de cualidades connotativas, así por ejemplo la representación del espacio uterino. Véase en Fortunata y Jacinta: I, VI, III, pgs. 246 y ss., entre otros. En La febre d'or: II, XIV, pgs. 467 y ss.

- Esa representación puede tener una transcendencia más amplia. La no identidad genera el concepto del laberinto como antítesis de la casa que refleja las ansias y la suerte de la existencia del personaje (caso de Fortunata y de Francesc). Igualmente, la casa es el espacio continente de la promiscuidad, de la transgresión. Véase, en Fortunata y Jacinta: I, VII, II, pgs. 286 y ss. y, en La febre d'or: I, XI, pgs. 138 y ss.

2 Véase: W.H.Shoemaker (1963-64): «Una amistad literaria: Ia correspondencia epistolar entre Galdós y Narciso Oller». Edt.: Boletín de la Real Academia de Buenas Letras, vol. XXX, pp.247-306. Barcelona.

3 Para la referencia de los textos remitimos a las siguientes ediciones: Oller, N.: La febre d'or. Pròleg de Carme Amau. Edt.: Edicions 62. Barcelona, 1994.

Pérez Gald6s, B.: Fortunata y Jacinta. Edición de Francisco Caudet. 2 volúmenes. Tercera edición. Edt.: Cátedra. Madrid, 1992.

4 En las sucesivas citas de la novela de Galdós indicamos: parte de la novela, capítulo, apartado y página. En las citas de la obra de Oller la referencia señala: parte, capítulo y página. 
- Cabe, en nuestro recuento, sin agotar todas las posibilidades de desarrollo de la casa pero sí centrándonos en las principales, una cuestión también presente en ellos: la dinámica de «hacer y deshacer la casa», como un motivo literario importante que encierra un valor metafórico. Una dinámica ésta consustancial al laberinto y generadora de nuevas aventuras narrativas. Véanse en Fortunata y Jacinta los capítulos siguientes: II, III, I, pgs. 519 y ss.; II, III, III, pgs. 530 y ss.; II, I, IV, pgs. 474 y ss.; II, II, VI, pgs. 482 y ss., entre otros. En La febre d'or: I, II, pgs. 34 y ss.; I, III, pgs., 47 y ss.; I, XI, pgs. 137 y ss., entre otros.

III.- De todas estas posibilidades nos detendremos en la última, con afán de desarrollarla más en profundidad: hacer y deshacer la casa como motivo literario y como metáfora. Esta dinámica también la encontramos en Balzac, en Histoire de deux jennes mariés 5 , novela que gira en torno a dos ámbitos privados, bajo la polaridad urbano-rural, como son el palacio de los Duques de Chaulieu en Paris donde habita Louise y el caserón del Valle de Gémenos en Provenza que terminan cruzándose a la par que sus protagonistas, acabando Louise en la isla de Ville-d'Avray, donde fallece, y Renée conquistando el espacio de la urbe parisina como Vizcondesa de L'Estorade. Por medio queda una dinámica de «hacer y deshacer la casa» unido a la aventura amorosa. También Dickens inserta en esta dialéctica al joven David/Trot Copperfield. Desde que le obligan a abandonar su casa de Bloonderstone, en Sooffolk, espacio al que va retornando asiduamente generando circularidades, va transitando por un conjunto de casas/habitaciones (Windsor Terrace, Dover, Londres...) con un componente purgativo y/o de iniciación que halla en su medio vital más amplio. Igualmente, Eça de Queiroz establece esta dinámica entre los protagonistas de Os Maias: Alfonso en Santa Olaria-Oporto, Pedro en Bemfica y Carlos en Ramillete, Lisboa. En torno a estos tres ejes, y a una dialéctica de hacer y deshacer su espacio representativo, gira una novela dinámica de espíritu trágico, de transición y cambio a través de sus tres protagonistas.

No ajenos a este motivo literario, Galdós y Oller, en castellano y en catalán, se hacen eco de estos moldes. Pensamos que estos son mínimos operativos, válidos para confeccionar razonablemente nuestro ejercicio comparatista, que realizamos contando con dos textos específicos, a la sazón los dos títulos más representativos de estos novelistas: Fortunata y Jacinta (1886) y La febre d'or (1890-92).

5 Rodolfo Cardona, en la edición de Doña Perfecta de B.P. Galdós (Edit. Cátedra. Madrid, 1997, nota 32, pg. 45), plantea la existencia de «patrones novelísticos» que sirvieron durante el siglo XIX a modo de modelos argumentales casi arquetípicos que facilitaban la creación novelística a los escritores. El profesor Cardona cita, a su vez, la referencia de S. Gilman donde hace constar la existencia de dos novelas de Balzac que pudieron contribuir a la concepción de Doña Perfecta. La utilización de tipos, gestos, situaciones que, a manera de módulos, facilitaban la creación literaria. A este planteamiento esencialmente comparatista, nos parece que podríamos vincular igualmente esta otra novela de Balzac, que guarda cierto paralelismo en los «espíritus literarios» de sus dos protagonistas, Louise y Renée, con los personajes femeninos de Fortunata y Jacinta. 
Al comienzo de la segunda parte en Fortunata y Jacinta, doña Lupe, la de los Pavos, y Maxi se han trasladado a vivir al barrio de Salamanca, espacio reservado a la nueva burguesía matritense. Cabe recordar que, de 1859 a 1865 , el marqués de Salamanca desarrolló una amplia actividad de inversiones en el barrio que llevará su nombre. El Plan de Ensanche de Madrid, aprobado en 1860 , hizo posible el proyecto de este barrio. Mientras la actividad industrial se circunscribía en Chamberí, la aristocracia en la Castellana y la población ruralproletaria en el sur, la burguesía lo haría en el barrio de Salamanca. La calle de Serrano comenzó a urbanizarse en la década de 1860 , construyéndose las dos primeras manzanas entre Villanueva y Jorge Juan, y entre ésta y Goya. La calle de Pajaritos (después " 29 de septiembre» y más tarde Ayala) fue abierta junto a otras calles como D. Ramón de la Cruz, Lista, Juan Bravo, etc., a finales de la década de 1870, como eje norte-sur de Serranot. La visión irónica de esa nueva burguesía nos la ofrece Galdós a través de la descripción de este espacio: "...vivía doña Lupe en aquella parte del barrio de Salamanca que llamaban Pajaritos (...). Púsose, pues, a zurcir en su sitio de costumbre, que era junto a la vidriera. Parece aquello un pueblo. La única distracción de doña Lupe en sus horas solitarias era ver quién entraba en el taller de coches inmediato o en la imprenta de enfrente, y si pasaba o no doña Guillermina Pacheco en dirección del asilo de la calle Alburquerque.» (II-III-III, pg.530). Nos muestra así un espacio desnudo que para nada encarna los nuevos ideales burgueses, más bien su antítesis, sobre todo si tenemos en cuenta el símil con el pueblo que establece el autor. ¿Dónde está aquel Galdós entusiasmado con una revolución burguesa que anuncia cambios sociales?

Recordemos algunos fragmentos de la carta que le escribe a Clarín, tras su viaje a París, publicados por C.Bravo-Villasante7: «...en el 67 se me ocurrió escribir La Fontana de Oro, libro con cierta tendencia revolucionaria. Lo empecé aquí y lo continué en Francia; al volver a España, hallándome en Barcelona, estalló la revolución. La acogi con entusiasmo. Después estuve algún tiempo como atortolado, sin saber qué dirección tomar, bastante desanimado y triste (no siendo exclusivamente literarias las causas de esta situación de espiritu)». Sobre estos mismos momentos hace referencia en las Memorias, la impresión sufrida por el joven Galdós es de las que dejan huella marcadísima en la vida: «Toda España estaba ya en ascuas. Barcelona, que siempre fíguró en la vanguardia del liberalismo y de las ideas progresistas, simpatizaba con ardorosa efusión en el movimiento... A los pocos días de presenciar en la Puerta del Sol la entrada del general Serrano vi la entrada del general Prim, el héroe popular de aquella revolución. El delirio de la multitud llegó al frenesìs.

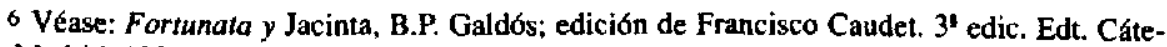
dra. Madrid, 1992, nota 12, pg. 457.

7 Las siguientes citas que aparecen en el texto pertenecen a: Bravo-Villasante, C. (1976): Galdós visto por sí mismo. Editorial Magisterio Español, S.A., colección Novelas y cuentos. 2" edición. Vitoria, pp. 45, 47 y 174, respectivamente. 
En los años en los que escribe Fortunata y Jacinta, Galdós está preocupado por el problema social. Su visión de España es resignada y escéptica, como lo reflejan las crónicas periodísticas escritas por esas fechas. La inutilidad de las soluciones políticas para los grandes problemas sociales y el remedio del espiritualismo, dan por resultado la creación de algunas extraordinarias figuras en la novelística galdosiana. Algunos ejemplos de todo esto son la figura del médico en La desheredada y en El doctor Centeno. En contraposición, la burguesía queda ridiculizada en las figuras de Juanito Santa Cruz, doña Lupe, Maxi, etc. Su nuevo espacio es descrito desde una valoración negativa, como hemos visto anteriormente. Frente al espacio masificado del proletariado cuyo máximo exponente es la corrala de la calle Mira el río, el de la burguesía es solitario, en el barrio de Salamanca. El autor trasciende así la realidad en un símbolo.

El espacio interior de la casa de doña Lupe representa la tiranía y la opresión que ejerce ésta sobre su sobrino, la criada y Torquemada. Una de las imágenes que reflejan esta realidad novelistica se ofrece en el gabinetito en que encierra doña Lupe a Maxi, con el retrato del difunto esposo colgado en el sitio presidencial, y donde pronuncia la frase lapidaria de: “...ya puedes ir a quitarte las botas. Estás preso...» (II-III-I, pg. 519). Es frecuente en toda la novela, y en esta escena ocurre igual, que cuando Galdós quiere llevar a los personajes a una situación de tensión, el suelo o las paredes son las receptoras de la mirada reprimida. Actúa así el espacio como catalizador de la tensión de los personajes y sus emociones: Maxi «Dejó esparcir sus miradas por la pared testera, como buscando por allí un apoyo. En ciertas situaciones apuradas y en los grandes estupores del alma, las miradas suelen fijarse en algo insignificante y que nada tiene que ver con la situación.» (II-III-I, pg. 520-21). Como consecuencia de la opresión de doña Lupe a Maxi nace en éste la idea de revelarse, de huir y de desear construir (hacer) su casa con Fortunata. El espacio se temporaliza a través de la mirada, buscando una idea, una salida. Igual que le ocurre a Fortunata con su pícara idea, es una puerta que abre a un nuevo espacio: «La mirada del joven revoloté por la estrecha cavidad del cuarto (...). Un movimiento de alegría y la animación de la cara indicaron que Maximiliano había atrapado la idea... Sobre la cama se esparcieron las tripas de oro, plata y cobre.» (II-I-V, pg. 474-75).

Al igual que el espacio se temporaliza el tiempo se espacializa en la novela, se refleja en las distintas casas que van habitando doña Lupe y Maxi: barrio Salamanca, Chamberí y calle Ave-María. Aparece así una correlación espaciotemporal en torno a la vida privada. La llegada de Fortunata a Madrid y su presencia bajo los vivos deseos de mejorar su personalidad, es la primera referencia a la idea de purificación de ésta, uno de sus dos polos sobre los que gravita: purificación (vida matrimonial) - amor pasional (destrucción). Esta dualidad también está asociada a otra respecto al personaje de Fortunata, nos estamos refiriendo a su aparición y desaparición del espacio escénico de la novela, otro movimiento dual: en Madrid con Juanito cuando la conoce - fuera de 
Madrid- vuelta a Madrid donde tiene el hijo nacido de ambos que se le muere - fuera de Madrid - vuelve a Madrid (con Maxi).

La idea de purificación se construye desde la ropa y el agua. La ropa es la que permite adecentarse y el agua permite pulirse. Del encuentro de Fortunata y Maxi surge el primer movimiento de hacer la casa. Toman un cuarto de alquiler en la calle Pelayo: "Quedó convenido entre Fortunata y su protector tomar un cuarto que estaba desalquilado en la misma casa. Rubín insistió mucho en la modestia y baratura de los muebles que se habían de poner, porque... (para que se vea si era juicioso) «conviene empezar por poco». Después se vería, y el humilde hogar iría creciendo y embelleciéndose gradualmente.» (II-II-I, pg. 480 ). Este acto se inicia desde el hecho simbólico de romper Maximiliano su hucha que contiene los tres tipos de monedas: oro, plata y cobre (II,I,V, pg. 475). Símbolo de su liberación que arrastra igualmente la sensación de culpa (humor irónico galdosiano): en el espacio cerrado de su habítación, el «asesino» esparce las tripas (de su hucha) sobre la cama, tirando los «despojos sangrientos», envueltos en un pañuelo, a la calle. Galdós, pese al insistente machaconeo de la crítica literaria por remarcar su realismo, dota a muchas escenas de un logrado simbolismo muy comunicativo. En este caso, la liberación de Maximiliano Rubin entraña un desgarre sangriento y violento desde el plano del símbolo, que a su vez actúa como una señal premonitoria sobre la evolución del personaje en la novela: «Los cascos esparcidos (de la hucha) semejaban pedazos de un cráneo, y el polvillo rojo del barro cocido que ensuciaba la colcha blanca pareciole al criminal manchas de sangre(...) Aquellos cascos, ¿dónde los echaría? He aquí un problema que le puso los pelos de punta al asesino. Lo mejor era envolver aquellos despojos sangrientos en un pañuelo y tirarlos en medio de la calle cuando saliera.» (II-1-V, pg.475-76).

La descripción de la primera casa de Fortunata viene a coincidir con las primeras descripciones de ella. Sobre su pasado tan sólo se menciona que su difunto padre poseía un cajón en la plazuela y su madre tenía el tráfico de huevos, y que ambos murieron cuando ella tenía doce años. Dos elementos utiliza Galdós para caracterizar a Fortunata, uno de ellos es la ropa, sus trapos: «iLos trapos, ay!. ¿Quién no ve en ellos una de las principales energías de la época presente, tal vez una causa generadora de movimiento y vida?...vuestra mente os presentará entre los pliegues de las telas de moda todo nuestro organismo mesocrático, ingente pirámide en cuya cima hay un sombrero de copa; toda la máquina política y administrativa, la deuda pública y los ferrocarniles, el presupuesto y las rentas, el Estado tutelar y el parlamentarismo socialista.» (I-II-Vpg. 153). Agua y tejido están muy presentes en la novela, como ya hemos comentado. La primera, como metáfora de la culpa, el acto de limpiarla, como se aprecia en el convento de las Micaelas. Madrid es inicialmente, para Galdós, «...el lugarón, la aldeota indecente», sin embargo más adelante comenta: «Por fin Madrid, dentro de algunos años, iba a tener raudales de agua distribuidos en las calles y plazas, y adquiriría la costumbre de lavarse, por lo menos, la cara y las manos. Lavadas estas partes, se lavaría después otras. Este Madrid, que 
entonces era futuro, se le representó con visiones de camisas limpias en todas las clases, de mujeres ya acostumbradas a mudarse todos los días, y de señores que eran la misma pulcritud.» (I-II-V, pg.154-55). Es el mismo deseo que manifiesta Fortunata cuando conoce a Maxi, su deseo de purificarse. Agua y tejido son dos elementos primarios. El tejido también está vinculado primariamente con la culpa: tras cometer el pecado, al comer la fruta prohibida, Dios expulsa del Paraíso a Adán y Eva: «Hízoles Yavé Dios al hombre y a su mujer túnicas de pieles y los vistió...» (Génesis 3,21).

El segundo rasgo con el que caracteriza, en parte, a Fortunata es a través del lenguaje, aspecto ya utilizado por Ramón de la Cruz y posteriormente por Arniches. Son pequeñas disertaciones metalingüísticas que introduce Galdós respecto del personaje: «Sus defectos de pronunciación eran atroces. No había fuerza humana que le hiciera decir fragmento, magnífico, enigma y otras palabras usuales. Se esforzaba en vencer esta dificultad, riendo y machacando en ella; pero no lo conseguía. Las eses finales se le convertian en jotas, sin que ella misma lo notase ni evitarlo pudiera, y se comía muchas sílabas (...) No se dice difirencia, sino diferencia. No se dice Jacometrenzo, ni Espiritui Santo, ni indilugencias. Además escamón y escamarse son palabras muy feas, y llamar tiologías a todo lo que no se entiende es una barbaridad. Repetir a cada instante pa chasco es costumbre ordinaria, etc...) (II-IIVI, pg. 482-3). Hay una identidad social a través del lenguaje y esa es la principal función de esas disertaciones, siempre en boca de algún personaje, dirigidas por un narrador muy presente.

Esta primera casa de Fortunata y Maxi, que hemos mencionado anteriormente (calle Pelayo), la podemos analizar desde el eje de la verticalidad. Por un lado, desde un plano real y social de la época, ya que las clases sociales cuanto más desfavorecidas eran ocupaban los pisos más altos de un Madrid que no pasaba de cuatro o seis alturas como máximo. Por otro lado, siguiendo el planteamiento topofílico de G.Bachelard en La poética del espacio, la parte alta de la verticalidad espacial, dentro de un espacio vivido, plantea una vigilia que se conecta con el mundo del deseo. En este caso el deseo de ambos, Maxi y Fortunata, por romper con su presente inmediato y construir un futuro distínto: «En uno de los segundos exteriores vivia Feliciana, y Fortunata en un tercero interior. Lo alquilo Rubín por encontrarlo tan a mano, con intención de tomar vivienda mejor cuando variaran las circunstancias." (II-II-III, pg. 489). Esta casa se deshace con motivo de ingresar Fortunata en el convento de las Micaelas, espacio de la purificación. Posteriormente, tras la boda de Maxi y Fortunata, surge el segundo movimiento de hacer la casa, esta vez en la calle Sagunto. Espacio que aparece desde sus inicios amenazado por Juanito Santa Cruz que ha alquilado el cuarto de al lado. Finalmente será un espacio profanado y violado en el que la puerta cobra una gran significación, como también la tiene en las Micaelas para Mauricia la Dura.

La puerta, en el nuevo domicilio de Fortunata y Maxi, en la casa purificada, y las escenas descritas a través o por medio de ella simboliza una fuerza 
sexual. G. Bachelard, en el libro mencionado anteriormente, establece la visión de la puerta como todo un cosmos de lo entreabierto. Es por lo menos su imagen princeps, el origen mismo de un ensueño donde se acumulan deseos y tentaciones, la tentación de abrir el ser en su trasfondo, el deseo de conquistar a todos los seres reticentes. La puerta esquematiza dos posibilidades fuertes, que clasifican con claridad dos tipos de ensueño: cerrada, con los cerrojos echados, o abierta de par en par. Fortunata se mantiene en una actitud vacilante entre el deseo de ser poseída (que Juanito abra la puerta) y la represión de este deseo (impedir que Juanito la abra). Entre la pasión y la purificación, de nuevo la misma dualidad que constituye la esencia del comportamiento de Fortunata. Recogemos a continuación los aspectos más significativos de esta escena, interpolando en el texto de Galdós, entre paréntesis y subrayado, las nociones a las que va remitiendo el episodio: "Llamaron a la puerta(...) Desde la cocina oyó Fortunata cuchicheo en la puerta(...) creyó sentir ruido en la puerta. Parecía como si cautelosamente probaran llaves desde fuera para abrirla(...). Observó entonces que el cerrojo no estaba echado, y lo corrió con mucho cuidado para no hacer rujdo(...). Ahora empujan(...). Es el viento que rebulle en la escalera(...) creía ver, cual si la puerta fuera de cristal(...). Tocó el cerrojo para cerciorarse de que estaba corrido, y se fue a la sala(...). En todo caso, es demasiado pronto, pensó Fortunata (deseo). Fue como una concesión a las ideas malas que con tanta presteza surgían de su cerebro(...). Resueltamente, mañana le digo a mi marido que la casa no me gusta y que es preciso que nos mudemos (represión). Y a esta sinvergüenza la planto en la calle -Patricia su sirvienta y aliada de Juanito Santa Cruz-(...). Fortunata se levantó y saliendo de la sala se acercó a la puerta(...). Apljcó el oído a la rejilla(...) llevó la mano al cerrojo(...) apartó su mano del cerrojo, el cual tenía el mango tieso hacia adelante como un dedo que señala (símbolo fálico). Entonces, por los huecos de la rejilla, de fuera adentro, penetraron (penetración) estas palabras adelgazadas por la voz: Nena, nena(...)ahora si que no te me escapas (...). Después sintieron que se abría y se cerraba la puerta del cuarto vecino(...) sintieron que se abría otra vez la puerta de la izquierda. Corrió Fortunata al ventanillo, miró con cuidado y (...) el otro salía embozándose en su capa (...). La emoción que sintió al verle fue tan grande (...). Hacía tres años que no le había visto(...). Y allá de madrugada fue vencida por el sueño, y se le armó en el cerebro un penoso tumulto de cerrojos que se descorrían, de puertas que se franqueaban, de tabiques transparentes y de hornbres que se colaban en su casa filtrándose por las paredes.» (II, VII, IV, pgs. 677-68I).

La casa tiene la misma correspondencia que el cuerpo de una mujer. Está muy marcado el rasgo de la penetración a través de la puerta y de las paredes en el sueño que, por otro lado, viene a representar la materialización de un acto sexual que Fortunata ha deseado y que no se ha cumplido con esa marcha de Juanito. Fortunata acepta su deseo por Juanito y esto la llevará a abandonar la casa marital y, por tanto, a deshacer la casa. La penetración en la mujer está simbolizada por la penetración en el espacio. 
La puerta es, a su vez, el lugar en el cual Fortunata le dice a Maxi que su relación se acabó, donde rompe, deshace para volver a hacer con Juanito; y también está asociada, la puerta, a la impotencia sexual de Maxi. Toda la simbología de la obra nos lleva a valorar a Galdós más allá de la etiqueta de autor realista. Crea un fuerte contraste entre las dos casas que habitan Maxi y Fortunata. La primera como espacio de tránsito, cuyos muebles son de alquiler y donde aparece Fortunata, como ya hemos mencionado anteriormente, bajo un fuerte deseo de honradez y purificación de su pasado. Por el contrario, la segunda vivienda, el espacio matrimonial que ocupan tras la purificación de Fortunata en el convento de las Micaelas, tiene buenas vistas y no es un interior, los papeles de la pared son nuevos, la alcoba estucada... Y el espacio del adulterio, la casa de Juanito y Fortunata en Cuatro Caminos, tiene una decoración más impersonal: «...tenía ese lujo allegadizo que sustituye al verdadero allí donde el concubinato elegante vive aún en condiciones de timidez y más bien como ensayo. Había muebles forrados de seda y cortinas hermosas; pero aquellos eran feotes, de amaranto combinado con verde-limón; las cortinas estaban torcidas... y otras mil porquerías con pretensiones de lujo y riqueza, todo ello anterior a la transformación del gusto que se ha verificado de diez años a esta parte. Santa Cruz miraba esta sala con cierto orgullo, viendo en ella como un testimonio de su estupidez.» (III-III-I, pg. 77).

Hasta aquí, tenemos tres casas que se hacen y se deshacen, esta última debido a que Juanito huye de ella. La cuarta es la que pone Feijoo a Fortunata en el distrito de La Latina, cerca de la Ronda de Toledo, en la calle Tabernilles (Puerta de Moros): «...que para los madrileños del centro es donde Cristo dio las tres voces y no le oyeron» (III, IV, IV, pg. 104-5). Es un cuartito modesto en un barrio apartado. El barrio parece un pueblo poblado por vecinos modestamente acomodados: asentadores, placeros, trajineros. Simboliza el espacio del destierro de Fortunata en el panorama matritense: «Es aquel barrio tan apartado, que parece un pueblo. Comunícase, de una parte con San Andrés, y de otra con el Rosario y la V.O.T. El vecindario es en su mayoría pacífico y modestamente acomodado; asentadores, placeros, trajineros. Empleados no se encuentran allí, por estar aquel caserío lejos de toda oficina. Es el arrabal alegre y bien asoleado, corriéndose al Portillo de Gilimón, se ve la vega del Manzanares, y la Sierra, San Isidoro y la Casa de Campo.» (III,IV,IV, pg.105). Esta casa se deshace para volver Fortunata a la calle Ave-María con doña Lupe y Maxi, y de ahí pasar, retornar, a la Cava de S. Miguel donde morirá.

Esta dialéctica de hacer/deshacer la casa es consustancial al personaje de Fortunata, un personaje ambivalente que se mueve entre dos polos. Por un lado una vida normativa y ordenada para la cual pasa por un proceso de purificación interior y que se materializa a través de su vida matrimonial con Maximiliano Rubin. Por otro lado, está su vida pasional y transgresora, materializada principalmente con Juanito Santa Cruz. Este segundo impulso vital aparece como dominante y de ello el espacio se hace eco: cuando posee su espacio marital, pasea Fortunata por la calle Santa Engracia y ve las casas pobres, y sus gentes, 
del barrio de las virtudes, entonces es cuando comprende que ella tiene un espacio natural, unas raíces que la atraen: «Le causaba envidia. Semejante vida no podía ser para ella, porque estaba fuera de su centro natural». Al encontrarse con Juanito le muestra sus señas de identidad: «...yo no me civilizo, ni quiero; soy siempre pueblo; quiero ser como antes, como cuando tu me echaste el lazo y me cogiste... Mi marido eres tú...todo lo demás...jpapas!» (II-VII-VI, pg. 690).

La misma metáfora de hacer/deshacer la casa la encontramos en La febre $d^{\prime}$ or. Recordemos, en primer lugar, que Foix vive en el segundo piso de la calle Gíriti, desde donde arranca la novela: «...se n'endugué la família a Barcelona, i s'establí en un segon pis del carrer d'En Giriti, bastant fose i petit...Allí, en aquell modest despatx on es trobava ara...allí veié aparèixer sos primers clients(...). En Gil Foix tenia ja, a més a més, un nen de quatre anys, un successor que perpetuaria son nom, sa fortuna.» (I, II, pg. 34). Un piso pequeño y oscuro que invita al cambio de vivienda, a deshacer la casa, unido todo ello a los nuevos proyectos de Gil Foix y a los nuevos rumbos de la bolsa y la especulación. Tomamos la descripción del comedor para ir contrastando las distíntas casas que va a ir habitando la familia de Foix. El comedor de la calle Gíriti nos lo describe Oller como: «El parament del menjador era tan pobre i menestral com el despatx que aquells dos homes acabaven de deixar. Una senzilla lira de gas il-luminava aquelles parets ointades d'un color torrat amb escrostonaments a l'alçada de les cadires. Aquestes eren de caoba i jonc, ja ennegrides per l'ús, i no passaven de vuit. Quatre n'hi havia a l'entorn de la taula, que era rodona i estava col-locada al mig, davant per davant de l'armari de la pisa; un armari ben proveit, però de peces de poc preu $i$ de bastant mal gust. El parament de la taula brillava, no obstant, net i polit, sota la lira del gas, que destriaya sa llum en els coberts d'argent, les copes de mig cristall, els plats de pisa blanca amb filets blaus, i el porró de cristall, hipòcritament batejat de tassa, amb què l'antic fuster bevia encara, a desgrat de la Delfineta, sa filla(...). ¿Què us semblaría si us digués que potser mudarem de pis)?(...) Remuntem la casa, emprenguem més operacions, establim unes oficines elegants: fugi d'aquest carrero. Avui la gent vol una altra cosa: es paga molt de les apariències.» (I, II, pgs. 39 a 44).

Deshacer una casa implica hacer otra, en este caso Foix se traslada al primer piso de la calle Ancha: «Era ja migdia quan en Gíl Foix(...) trucava a la porta de sa nova habitació, un primer pis del carrer Ample(...). Allò sí, que era ésser ric!(...). Un pis amb dues portes: la que acabava de passar, amb la gran planxa d'acer Gil Foix, i, davant, la de la família, aquella a què ell trucava, seriosa, sense inscripcions, de roure artisat, neta i brunyida com tot son joc de níquel(...). La mamà i la Fina eren allí, en aquell menjador empaperat de color de malva, guarnit amb un esplèndid mirall damunt l'escalfa-panxes encès, un gran tinell de noguera, altes cadires del mateix encoixinades de cuiro, folgades cortines de llana i seda a cada obertura, mirífica làmpara de bronze penjant del sostre, i tofuda catifa blava amb sanefa vermella a terra.» (I, III, pgs. 47-48). 
Al comparar un comedor con el otro, contrasta la pobreza y deterioro del primero con el lujo y el esplendor del segundo. Uno tiene las paredes desconchadas mientras que el otro tiene las paredes empapeladas de color malva. Las sillas de caoba y junco ennegrecidas contrastan con las altas sillas de nogal con asiento y respaldo de cuero, o la sencilla lira de gas con la lámpara de bronce pendiente del techo. Como se puede apreciar, el espacio apoya toda la intención de la escena. Al hacer la nueva casa se inicia un nuevo mundo para la familia de Gil Foix y, a su vez, da paso a la trama de la novela.

Este nuevo mundo que se simboliza a partir de hacer la nueva casa se viene abajo con la caida de la bolsa. La destrucción implica deshacer la casa para cobijarse en otra que se ha ido haciendo a lo largo de la obra, el piso de la señora Mónica y Francesc, en la plazuela de Fegomir. Este cuarto piso es el que, al final de la novela, ampara a Gil Foix y alberga el matrimonio de Francesc y Delfineta. Si anteriormente Oller nos ha descrito el lujo del comedor del piso de la calle Ancha, ahora, en el piso de la plazuela de Fegomir, en lugar de describirlo se limita a denominarlo «comedorcito» y zanja así la necesidad de crear su imagen para el lector, aunque asociándolo a un espacio pequeño y sencillo: «La senyora Mònica, que estava llavors cabdellant una trocaal peu del balcó del menjadoret...» (I, XI, pg. 137).

A través del protagonista de la novela, Gil Foix, se materializa la metáfora de hacer/deshacer la casa. Hasta aquí Oller ha ido creando la trayectoria vital del personaje sobre la construcción y destrucción de tres pisos: el de la calle Gíriti, el de la calle Ancha y, finalmente, el de la plazuela de Fegomir. Ya hemos hecho referencia anteriormente al carácter fundacional de Foix, que se proyecta igualmente sobre la fundación de su casa: «Sou el fundador d'aquesta casa, i avui, avui acabem sos fonaments o l'ensorrem per sempre!(...). Jo seré bo, jo en faré bon ús: vos ho prometo!.» (I, XIV, pg. 185). No hemos considerado en nuestro análisis la casa que Foix compra a Catarina en Vílaniu porque no es significativa en la trama de la novela: «Ja veu que encara no hem obert l'establiment: eh? Doncs només sabent que estenc el negoci, i que he comprat una casa per a la Catarina a Vilaniu, ja no es pot figurar la clientela nova que ha vingut, (I, III, pg. 57).

Otros espacios que se hacen en la novela son el hipodromo, el piso de Rodón en la calle Lauria (Barcelona), y la torre de Giró, en Pedralbes. Estas dos últimas casas también se deshacen como consecuencia de la crisis bursátil y del caos espacial que comporta, trayendo la bancarrota de sus propietarios. Frente a estos espacios que se hacen y deshacen en la novela aparecen otros con un carácter más estático, como son la casa de Jordi y Eladi, y la del barón de Esmalrich.

IV.- Concluiremos que la dinámica de «hacer y deshacer la casa» es un motivo literario que se reproduce a lo largo de las obras, con ciertas modificaciones, a las que caracteriza. Recordemos las tres «casas" que ocupan doña 
Lupe y Maxi; Fortunata y Maxi o Foix y su familia (en la novela de Oller). Las dos que ocupan Juanito Santa Cruz, una de ellas con Fortunata; así como Rodón y Giró en La febre d'or, o las ocho «casas» en las que vive Fortunata, por referir los ejemplos más significativos.

Es una dinámica estructural y destacable del espacio narrativo y, formando parte de él, del urbano, por tanto, recurrente dentro del desarrollo novelesco. Este motivo también lo encontramos en otras novelas realistas o próximas a estos moldes, de las que ya hemos referido algunas entre la fecunda creación de este período. El sentido connotativo lo da el enlace del motivo con la lógica de Ja acción, con el germen temático, referencia caracterizadora de lo que se generaliza y descaracteriza, en cuanto función. El espacio va unido a la trayectoria vital de los protagonistas de las novelas, Fortunata y Gil Foix. Deshacer una casa, el cuarto alquilado por Maxi en la calle Pelayo o la de la calle Gíriti en la Barcelona de Foix, da paso a crear otra y con ello a una nueva aventura: la materialización de la relación entre Juanito y Fortunata en el piso de Cuatro Caminos o el enriquecimiento enloquecedor de Foix en la casa-oficina de la céntrica calle Ancha, con todo lo que ello va a representar para la trama. En este sentido coinciden Oller y Galdós, como grandes novelistas que son, creando una semejanza formal y de sentido entre el espacio y el personaje, utilizándolo a favor de la intención de sus respectivos discursos narrativos. Fortunata, en sus recorridos como figura errante por la ciudad galdosiana, transformada para ella en un laberinto, va trazando una aventura de incidencia cada vez más íntima que nos dirige hacia la formulación trascendente del psicologismo. Mientras que en las gestas de corte socialmente externo de Foix y -en su trayectoria bipartita, ejemplificadora y circular, ya que al final de su recorrido regresa a su condición inicial de carpintero-, se autolimita el alcance de su fícción a una circunstancias históricas, a la postre pasajeras. A partir de esta dinámica de hacer y deshacer la casa, se crea una paráfrasis del universo del ser humano a finales del ochocientos. 